\title{
Sourcing of Internal Auditing: An Empirical Study
}

\author{
Roland F. Speklé*, Hilco J. van Elten \& Anne-Marie Kruis \\ Erasmus University Rotterdam \\ Erasmus School of Economics \& ERIM \\ Room H14-31 \\ P.O. Box 1738 \\ 3000 DR Rotterdam \\ The Netherlands \\ e-mail: spekle@few.eur.nl \\ phone: +31 104081435 \\ fax: +31 104089171 \\ Working Paper, August 2005
}

\begin{abstract}
In recent years, the scope of internal auditing has broadened considerably, increasing the importance of internal auditing as part of the organization's management control structure. This expanding role has changed the demands being put on internal auditors. Their new role requires different skills and competencies, and many organizations now need to face the choice whether to develop these broader competencies internally or to outsource internal auditing to outside service providers.

This paper studies the factors associated with organizations' internal audit sourcing decisions, building from a previous study by Widener \& Selto (1999; henceforth W\&S). In their study, W\&S used Transaction Cost Economics (TCE) to explain the organization of internal auditing. Our study seeks to replicate their results, using newly collected data from 66 companies headquartered in the Netherlands. Our findings are supportive of W\&S. Like W\&S, we find asset specificity and frequency (both individually and in interaction) to be significantly associated with sourcing decisions in a regression model that explains $65 \%$ (adjusted $R^{2}=0.63$ ) of the variance in outsourced internal auditing. Additional analyses reinforce the importance of these TCE variables in explaining organizations' internal auditing sourcing behaviour.
\end{abstract}

Key words: Internal auditing; Transaction Cost Economics; Make-or-buy decision JEL codes: M4; D23; L22; L23

\footnotetext{
" Corresponding author.
} 


\section{Introduction}

Traditionally, the internal auditing function has been designed to help ensure reliable accounting information and to safeguard company assets. More recently, internal auditing has evolved to encompass operational auditing, risk assessment, IT assurance services, and more. This expanding role has increased the importance of internal auditing as part of the organization's management control structure. But is has also changed the demands being put on internal auditors. Their new role requires different skills and competencies, and many organizations need to face the choice whether to develop these broader competencies internally or to outsource internal auditing to outside service providers (Ahlawat \& Lowe, 2004; Widener \& Selto, 1999).

Over the last decade, this decision has been hotly debated in the professional literature. The debate over the benefits of organizing the internal audit function in-house versus the alternative of outsourcing this function to third party vendors (usually a public accounting firm) is not without partisan interests. Indeed, the debate can be seen as a jurisdictional dispute between the internal auditing and the public accounting professions over the right to control the provision of internal audit services (Rittenberg \& Covaleski, 2001; Covaleski, Dirsmith, \& Rittenberg, 2003). Public accounting firms have found the provision of internal audit services to be a lucrative market (Petravick, 1997; Rittenberg \& Covaleski, 1999). Some estimate that potentially, an accounting firm's revenues from internal audit services can be up to ten times that of annual financial statement audits (Aldhizer, Cashell, \& Martin, 2003). These firms justify their presence in the market for internal audit services by stressing their sophisticated expertise, flexibility, and cost-effectiveness (Caplan \& Kirschenheiter, 2000). Internal auditors, on the other hand, emphasize the importance of in-depth, organizationspecific knowledge, loyalty, and their role in handling crisis situations and fraud prevention (Barr \& Chang, 1993; Chadwick, 2000; Martin \& Lavine, 2000). This debate has gained additional momentum as in the wake of recent business scandals many organizations are currently reconsidering their internal audit functions -either voluntary or forced by new laws, regulations, and guidelines (the Sarbanes-Oxley Act, SEC-rules and their local counterparts all around the world). Although these new rules appear to favour in-house internal auditing as an integral part of the organization, outsourcing is still allowed provided -broadly speaking- that the organization retains management of the internal audit function and the contractor is not the external auditor. As for the future, most practitioners seem to accept -albeit sometimes grudgingly- that outsourcing is here to stay (Aldhizer et al. 2003; IIA, 1998).

In the academic literature, only a few studies address the factors that drive organizations' decisions to internalize or outsource internal auditing activities. In an analytical study, Caplan \& Kirschenheiter (2000) demonstrate that the choice between outsourcing and inhouse provision of internal audit services may be explained by the higher incentive intensity an outside vendor experiences. As public accounting firms can be sued following an audit failure, their stake in providing high quality services is high, and they may be expected to exert quite intense effort to prevent audit mistakes. Because employment contracts have an implicit but binding limited liability constraint, internal auditors who are employees of the organization cannot be exposed to incentives of similar strength. On the other hand, public accountants may have higher reservation wages. On balance, Caplan \& Kirschenheiter found 
that the incentive to outsource increases in various measures of risk, including the risk that a control weakness exists and the size of the loss that can result from an undetected control weakness.

The only empirical study we know of that addresses the specific factors associated with organizations' internal audit sourcing decisions is Widener \& Selto (1999). In their study, they used Transaction Cost Economics (TCE; Williamson, 1975, 1985, 1996) to explain the organization of internal auditing. Based on survey data collected from 83 firms based in the USA, they found that asset specificity and frequency -both individually and in interactionwere significantly related (inversely) to outsourcing. For several other hypotheses, especially regarding the role of uncertainty, they found no support. Their regression model explained $53 \%$ (adjusted $R^{2}=0.46$ ) of the variation in outsourced internal auditing.

Given the strength of their results, the Widener \& Selto study (henceforth referred to as W\&S) is an important contribution to our understanding of internal audit sourcing behaviour. However, as W\&S rely exclusively on US data, it is conceivable that the insights derived from this paper do not generalize to sourcing decisions in other institutional contexts. In fact, some may argue that the W\&S results cannot be generalized at all because of the relatively small size of their sample. Additionally, W\&S is based on data from the year 1996. Because both the conception of internal auditing and the role of this function in organizations seem to have changed quite considerably over the past few years, it is possible that the relations found by W\&S are no longer valid. For these reasons, our study seeks to replicate W\&S's results at a different point in time and in a different institutional setting. We provide new empirical evidence on firms' internal audit sourcing decisions, using data from 66 companies headquartered in the Netherlands. As our study is explicitly designed to build from W\&S, our hypotheses are also based on TCE, and are largely similar to those tested by W\&S, except for the influence of uncertainty which we predict to be insignificant. Our questionnaire is identical to W\&S except for some pruning and some minor modifications that allow us better to capture local conditions. Our findings are supportive of W\&S and strengthen their conclusions. Like W\&S, we find asset specificity and frequency (individually and in interaction) to be significantly associated with sourcing decisions in a regression model that explains $65 \%$ (adjusted $R^{2}=0.63$ ) of the variance in outsourced internal auditing. Several additional analyses reinforce the importance of these TCE variables in explaining organizations' internal auditing sourcing behaviour.

The structure of this paper is as follows. The second section uses TCE to identify and hypothesize constructs that may explain internal auditing sourcing decisions. The third section describes our research design and operationalizes the constructs. Section 4 presents the quantitative analysis. The final section provides conclusions and discusses this study's limitations, implications, and suggestions for further research.

\section{Hypotheses}

From a TCE perspective, sourcing of internal auditing is seen as a choice between two alternative modes of governance. These alternative governance structures differ in the control mechanisms they employ to safeguard contract execution. In-house provision of internal audit services subjects these activities to hierarchical control, which is primarily based on manage- 
rial authority, internal incentive structures, and monitoring. Outsourcing implies reliance on market discipline or perhaps on a hybrid mode of control -depending on the specifics of the contract. Because of these structural differences, each individual mode of governance has a distinctive problem-solving potential. But the alternatives also differ in respect of transaction costs. These include the costs of drafting, negotiating, and safeguarding the transaction, but also the (opportunity) cost of performance losses due to imperfect control. TCE suggests that economic agents seek to adopt governance structures that match their control needs in a cost-effective way. These control needs arise from the characteristics of human behaviour, of which bounded rationality and opportunism are especially consequential. Bounded rationality refers to man's limited cognitive and computational ability. Opportunism is "self-interest seeking with guile" (Williamson, 1985, p. 47), which may include calculated efforts to mislead and deceive. But the control needs also depend on the attributes of the transaction, i.e. on the score on asset specificity, uncertainty, and frequency. Specific assets are resources that are more valuable in their current use than in alternative uses. Asset specificity denotes the presence of opportunity losses that arise if the investments made to support the transaction are to be put to alternative uses or users. Uncertainty refers to the degree of specifiability of intended performance and predictability of the environment within which the contract is to be executed (environmental uncertainty), and to the problems contracting parties may experience in monitoring performance (behavioural uncertainty). Frequency represents the volume and value of the transactions over time. TCE's main idea is that "transactions, which differ in their attributes, are aligned with governance structures, which differ in their cost and competence, so as to effect an economizing result" (Williamson, 1999: 1090-1091).

\subsection{Asset specificity}

Specific investments are associated with differentiated products, services, or processes. The willingness to invest in specific assets is related to the value of this differentiation to the firm, net of cost differentials of both a production and transaction cost nature. Specificity, then, is present if there is no equally attractive alternative for a given means to achieve a given purpose (Nooteboom, 1993: 443). In some firms, specific investments may be required to perform the internal audit function ${ }^{1}$. For instance, it may be necessary to build a firmspecific knowledge base for the internal auditors to function effectively. They may need a rich and detailed understanding of the firm's operations, strategies, and corporate culture to be able to construct a meaningful audit strategy and to conduct the audit in a competent and informative way. This knowledge, however, is only valuable within the context of the firm to which it relates, and the costs associated with its acquisition can only be recovered in that particular context.

\footnotetext{
${ }^{1}$ At least to some extent, all auditing requires specialist knowledge. i.e. some degree of technical competence (Arruñada, 2000). This competence, however, is of a functional kind and does not necessarily involve asset specificity at the level of the auditor-auditee dyad because the functional expertise may be applicable (without loss of value) to a broad class of firms.
} 
The degree of asset specificity of internal auditing depends on the nature of the audits as such. For instance, a routine financial audit to review the reliability of accounting information relies on a generic, fairly standardized technology and its specificity will be relatively low. Operational audits and special projects on the other hand require a more tailored approach, taking into account organization-specific circumstances and considerations, and their specificity rises accordingly. But the degree of asset specificity also depends on the role played by the products of the audit efforts in managing the firm. Some firms seem to approach their internal audit function rather passively, viewing it as just another component of their financial control system with no special status. Others, however, attribute a more vital role to the internal audit function, emphasizing its value-adding contribution to the firm's operations, risk management, and control processes. In this latter view, internal auditing is much more integrated in the management of the organization, and it will rely more on strategically relevant information. In fact, it may even produce such information. In this more pronounced role, asset specificity is higher than in the case of internal auditing as a plain guardian of financial data reliability.

If internal auditing requires deep knowledge of the business and the company, firms will tend to internalize the internal audit function. Acquisition of such knowledge is best supported through thorough immersion in the organization, especially if the required 'business sense' resists codification and can only be gained in a learning-by-doing fashion. Also, potential external providers can only be persuaded to make the auditee-specific investments if they can secure a long term contract that allows them to recover their initial investments. Writing such contracts, however, is problematic because that requires firms to specify up front the properties of the audit services they desire over longer periods of time. In addition, firms would need to be able to explicate the necessary investments in firm-specific knowledge in legally enforceable terms, and would need to be able to assess whether their contracting partner actually makes these investments. When these conditions cannot be met, contracts will be incomplete, opening the door to opportunistic behaviour, e.g. shirking on effort and quality, underinvesting in firm-specific knowledge, or commanding increasing premiums for the services. In the presence of substantial asset specificity, the outsourcing firm cannot rely on market discipline to constrain such behaviour, because switching to another external provider (with no company-specific knowledge) would compromise audit quality -at least for the period of time required for the new partner to build up its knowledge base $^{2}$. If, however, the internal audit function requires no significant investments in firmspecific assets, market-mediated procurement of internal audit services is likely to be the more efficient alternative. Market exchange provides strong performance incentives, while reputation concerns in the market for audit services serve as a low-cost quality safeguard (Arruñada, 2000).

2 It is interesting to observe that these theoretical arguments -though cast in a different language- are also present in the professional debate. The Institute of Internal Auditors (IIA) for instance argues that the internal auditor's superior knowledge of the business favours inhouse sourcing, and points to the danger of becoming dependent on the outside provider as the external auditor gains more institutional knowledge about the organization (IIA, 1998). 
To summarize the discussion, our hypothesis is that when asset specificity of the internal audit function rises, firms will be more likely to internalize this function. Conversely, low asset specificity would motivate firms to outsource internal auditing (cf. also Widener and Selto, 1999). The asset specificity of internal auditing becomes manifest through investments in firm-specific expertise and training, the nature of the audit activities, the role of internal auditing, and its integration in the management of the organization. Therefore:

H1: Asset specificity of the internal auditing function is negatively associated with the degree of outsourcing.

\subsection{Environmental uncertainty}

Environmental uncertainty affects the degree of ex ante specifiability of desired performance and the predictability of (the influence of) the environment in which the contract is to be executed. Higher uncertainty inhibits a full ex ante specification of required performance, favouring governance structures that can secure smooth adaptation to unfolding conditions and emerging insights. The alternative modes of governance differ in the way in which they accommodate adaptation. In spot market contracting (i.e. the purest form of market governance), flexibility is achieved through autonomous unilateral adaptation to changing circumstances. When confronted with altered conditions, each party reconsiders its own position, and the market ensures that a new equilibrium is found in which new contracts fully reflect the novel conditions. Recurrent spot market contracting, however, requires low asset specificity. With higher levels of specificity, the market becomes too thin to induce convergent expectations, and successful adaptation presumes a coordinated rather than a unilateral response from contracting parties. Then, the hierarchy becomes the preferred governance mode. Its reliance on managerial authority provides the mechanisms for sequential adaptation and supports a cooperative response to changing circumstances ${ }^{3}$. Thus, TCE's standard position is that uncertainty reinforces the effect of asset specificity (cf. Boerner \& Macher, 2002; David \& Han, 2004): when asset specificity is present to a non-trivial degree, uncertainty tilts the balance in favour of internalization at lower levels of asset specificity than would otherwise be required to result in a preference for in-house sourcing. Conversely, if asset specificity is low, higher uncertainty strengthens the motivation to outsource.

We expect, however, that this general argument cannot be sustained in the specific context of our study. One reason for this is that internal audit sourcing is not a discrete choice between the extremes of complete outsourcing on the one hand, and full internal provision of these services on the other. Rather, firms can choose to internalize parts of the

\footnotetext{
${ }^{3}$ Hybrid governance is generally held to be infeasible in conditions of substantial uncertainty. In hybrid forms of governance, adaptations to unforeseen contingencies require renegotiations and mutual consent. For this reason, the hybrid mode cannot ensure a timely response to changing conditions, and failures to adapt predictably arise (Williamson, 1991). Moreover, such renegotiations provide an arena for opportunistic behaviour, which further undermines the hybrid's effectiveness in the presence of uncertainty.
} 
internal auditing function, and to rely on external providers for other internal auditing services. This co-sourcing option provides additional ways to deal with uncertainty; ways that are not captured by the default predictions of TCE. For instance, even if a firm's total package of internal auditing activities is highly specific, the internal audit department may still hire external assistance to cope with peaks in the demand for its services. In that case, outside contractors work together with the internal audit department, presumably handling the relatively unspecific parts of the total package. Similarly, the firm may choose to assign ad hoc projects that would overburden the capacity of the internal department to outside parties (e.g. implementation of "Sarbanes-Oxley").

Another argument that leads us to believe that TCE's standard position on uncertainty may lack relevance in explaining internal auditing sourcing decisions has to do with the basis of the hierarchy's advantage in handling adaptation when asset specificity is substantial. The hierarchy's ability actively to manage sequential adaptation to emerging conditions hinges critically on managerial involvement. For reasons that will be discussed more fully in the context of behavioural uncertainty (see section 2.3), we argue that in the typical organization this involvement cannot be realized for lack of auditing expertise at senior management levels. If this is true, the decision on whether and how to adapt to changing circumstances must essentially be left to the internal auditors themselves. Although senior management probably retains formal ratification rights, its influence will usually not extend beyond a rather passive, relatively uninformed 'pre-action review' (Merchant, 1985). This deprives the hierarchy of the benefits that are usually associated with its unique ability to support coordinated adaptation. That is to say, we can think of no compelling reason to assume that the effectiveness of a relatively uninformed pre-action review depends on whether the internal auditors that initiate the adaptation proposal are employees of the firm or outside contractors.

These issues probably warrant a detailed examination. However, our empirical study has been designed to capture the general thread of internal auditing sourcing and cannot address these finer points. Therefore, we leave the details to future research and stick to a coarser hypothesis:

H2: Environmental uncertainty does not affect internal audit sourcing decisions.

\subsection{Behavioural uncertainty, or information impactedness}

Up to this point, our discussion has focused on uncertainty as it relates to the desired properties of performance and the external circumstances affecting these properties. Uncertainty, however, may also have behavioural origins. Behavioural uncertainty is associated with strategic nondisclosure, manipulation of information, and -more generally- moral hazard and information asymmetry. Williamson uses the notion of information impactedness to refer to behavioural uncertainty. He conceptualizes information impactedness as a derivative condition that arises mainly from uncertainty and opportunism (Williamson, 1975). Parties to an exchange may possess or acquire private information that is relevant to contract execution or the assessment of performance. Such private information may be exploited at the expense of the other party. If asset specificity is low, competitive pressure effectively curbs opportunis- 
tic inclinations, and behavioural uncertainty is not a problem. With higher degrees of asset specificity, however, behavioural uncertainty poses serious contracting hazards. In the case of internal auditing, such hazards are particularly real. At least to some extent, internal auditing is a specialist function, requiring specialized skills and competencies. Therefore, internal auditors tend to have significant autonomy and exert considerable influence on what to audit and how to audit it. Also, the internal auditors' job involves a great deal of professional judgement, and the evidence from which they work cannot always be explicated fully. For instance, their reports may partly be based on personal observations, interviews, and visual on-site inspections. For these reasons, audit reports document their efforts imperfectly, and the quality and efficiency of their work cannot fully be ascertained from these reports (cf. Arruñada, 2000). The fact that auditors often work at remote locations, physically separated from one another exacerbates these problems of observability and verifiability. This puts them in a position to shirk on effort and quality (cf. also Caplan \& Kirschenheiter, 2000; Widener \& Selto, 1999).

In conditions of non-trivial asset specificity, the standard TCE prediction is that higher behavioural uncertainty increases the attractiveness of internalization. The argument is that internal organization brings better monitoring, enhancing observability of effort and performance quality. Also, internal organization weakens incentive intensity, alleviating the problem of opportunism (Williamson, 1975). In their study of internal auditing sourcing, W\&S adopt a similar view. They hypothesize that if firms experience problems in observing the quality of idiosyncratic internal auditing, they are even more likely to internalize the audit function (Widener \& Selto, 1999). We take a different position. Our point of view is that the standard TCE approach may well overestimate the relative benefits of internalization in coping with conditions of information impactedness -at least in the context of internal auditing. Internal auditing of the firm-specific type is a specialist function, involving expert knowledge and technical competence, professional judgement, and considerable discretionary decision-making authority on the part of the internal auditor. A positive assessment of the effectiveness and efficiency of the internal audit function requires a detailed and costly examination of audit operations by an extremely knowledgeable monitor, who effectively needs to be an auditing expert him- or herself. Such expertise will not typically be available to senior management. Absent such expertise, control of the internal audit function is limited to a form of boundary control, which is a very weak form of control emphasizing the prevention of unwanted actions or outcomes, rather than actively supporting desired contributions (Speklé, 2001). Therefore, internalization offers no clear advantages in terms of monitoring the performance of the internal audit function. Accordingly:

H3: Behavioural uncertainty does not affect internal auditing sourcing decisions.

To further buttress this hypothesis, it is important to note that even if firms outsource their internal audit function, recent regulations and guidelines (in the USA as well as in the Netherlands and in many other countries) require them to retain the top internal audit position inside the firm. For instance, AICPA ethics rulings forbid public accounting firms providing outsourcing services to assume ultimate management responsibility for the internal audit function. Hence, the ability of senior management to monitor the individual who has 
overall responsibility for the internal audit function (the chief auditor) appears unaffected by the sourcing decision (Caplan \& Kirschenheiter, 2000). In addition, even if internalization allows for better monitoring, this advantage may be offset by the incentives outside providers experience. Because the external auditor's reputation is a valuable asset, it is costly for external service providers to risk their reputation by reneging on promised performance quality (Arruñada, 2000; DeAngelo, 1981). For this reason, monitoring is less critical in an outsourcing situation than in the case of internally serviced internal auditing needs.

\subsection{Frequency}

TCE submits that governance structures are aligned with transactions in a discriminating, transaction cost economizing way. There are, however, set-up costs involved in matching the structure to the transaction. Obviously, these costs must be weighted against the benefits of better governance. Frequency refers to the volume and value of a particular transaction over time, and affects the economic rationality of investing in specialized governance. As recurrent or more valuable transactions provide a larger basis against which to charge the extra costs of specialized governance (Williamson, 1985), higher frequency supports the emergence of tailored control.

An implication of this argument is that as frequency rises, firms develop a preference for in-house sourcing at lower levels of asset specificity than would otherwise be required to tilt the balance in favour of internalization. Or to approach the issue from the opposite angle: frequency considerations may keep companies from internalizing the internal audit function even if they would prefer to do so because of high asset specificity. In-house provision of internal audit services requires firms to invest in audit expertise and in training and development to keep this expertise up-to-date. As the scope of internal auditing is expanding and internal auditors have to confront increasing demands on their competence and skills, these investments become considerable. By their nature, such investments carry significant economies of scale, and the demand for internal auditing services must be sufficiently large to be able to recover the investments. In fact, we expect that only the largest users of internal auditing services are able fully to internalize the audit function if they wish to do so. The reason for this is that internal auditing is becoming increasingly more advanced and specialized in terms of technical competence, so that only the larger firms can afford to keep the necessary specialties on staff ${ }^{4}$. For example, few firms are able to manage IT-auditing entirely in-house.

In line with these arguments, we expect firm size and frequency of internal auditing use to interact with asset specificity, affecting internal auditing sourcing decisions. More specifically:

\footnotetext{
${ }^{4}$ The professional literature echoes this argument. Thus, the Institute of Internal Auditors expresses the belief that the internal auditing function is best performed by a fully resourced and competent staff that is an integral part of the organization, but recognizes that smaller firms find it difficult to attract and retain competent staff, and that smaller internal auditing shops are unable to keep up with increasing demands for specialization (IIA, 1998).
} 
H4: The effect of a change in asset specificity on the degree of outsourcing is larger when frequency is low than when frequency is high.

Although in theoretical TCE per se frequency is presented primarily as a moderator variable, we also hypothesize that firm size and the intensity of internal auditing have a direct effect on the sourcing decision: as the volume of internal auditing increases, differences in production costs between internally sourced auditing activities and outsourced auditing diminish, simply because larger internal auditing departments are better equipped to capitalize on economies of scale than smaller ones. Therefore:

H5: Firm size and the frequency of internal auditing use are negatively associated with the degree of outsourcing.

\subsection{Summary of expectations}

Figure 1 visualizes the relations in the theoretical model and summarizes our expectations.

\section{[TAKE IN FIGURE 1 ABOUT HERE]}

\section{Research design and measurement}

\subsection{Research design and sample}

In absence of publicly available archival data on firms' internal auditing sourcing decisions and most of our independent variables, our study required extensive data collection using survey methods. Since our study seeks to replicate W\&S, our initial questionnaire was identical to W\&S. We discussed this questionnaire with knowledgeable employees of a major external provider of internal auditing services to check for clarity and relevance. This led to some pruning and a small number of minor modifications that helps us better to capture local conditions. The final survey was mailed to the CFO's of the 450 largest companies (in terms of number of employees) headquartered in the Netherlands ${ }^{5}$. This resulted in 131 responses (29\% overall response rate). Of these respondents, 56 reported that they did not use any internal auditing services. Of the remaining 75 responses, 66 (15\% of the original sample of 450 firms) were useable. Obviously, the (useable) response rate is quite low. However, it does not compare unfavourably to similar survey-type studies in the management accounting and control literature. For instance, W\&S got a response rate of $14 \%$. Also, because 56 respondents ( $12 \%$ of our original sample and $43 \%$ of respondents) report not to use internal auditing, our useable response rate as calculated above underestimates the extent to which our final sample covers the population of firms that actually use internal auditing.

We compared the scores of responding firms on sales and number of employees (both of which are variables that the study uses as archival proxies for TCE variables) to those of

\footnotetext{
${ }^{5}$ The companies were identified using the REACH database, which is also the source of the archival data we rely on in the analysis.
} 
the original sample of the 450 largest firms. Using ANOVA, we find no significant difference in the scores on these variables between respondents and the full sample. Neither are there any significant differences between early and late respondents. Furthermore, the distribution of our respondents over industries is broad, and roughly similar to the distribution in the total sample. Thus, we have no indication of a non-response bias.

\subsection{Measurement of variables}

The dependent variable is the proportion of outsourcing of internal auditing activities (PROP OUT). Scores for this variable are calculated by dividing the number of hours of outsourced internal auditing by total number of hours of internal auditing.

The independent variables used in the analyses are asset specificity (AS), frequency (FREQ), environmental uncertainty (EUNC), and behavioural uncertainty (BUNC). The questionnaire contains 12 items that were designed to pick up different aspects of asset specificity. Examples are the amount of operational versus financial audits, use of proprietary information, and the role of internal auditing in relation to the achievement of strategic goals. Respondents answered these questions for both internalized activities and outsourced activities. The responses are differenced so that the score reflects the importance of internalized internal audit in relation to that particular item. Reliability analysis conveys that nine of these items load on a single factor. Therefore, we combine these items by calculating the mean difference between the scores for internal and outsourced activities to obtain a single score for asset specificity. The correlation of the other three items with the factor was too low (or even negative) and we dropped these items from the analysis. Table 1 provides further details.

Frequency is measured by two archival proxies, plus two questionnaire items: sales, number of employees, number of internal audit reports, and the number of internal audit engagements (see table 1 for full details). Because of the vastly different measuring scales of the individual items, we standardized the scores, and our proxy for frequency is measured by computing the mean of the standardized item scores.

\section{[TAKE IN TABLE 1 ABOUT HERE]}

The survey measures environmental uncertainty by (1) the variation in business activity, and (2) the predictability of the need for internal auditing. These items are uncorrelated and we enter them into the analyses as separate variables (EUNC ${ }_{1}$ and $E U N C_{2}$ respectively). We sought to measure behavioural uncertainty using two items: (1) verifiability of outsourced contract performance, and (2) the degree of difficulty of evaluating the quality of outsourced internal auditing relative to internally sourced auditing. However, due to the large number of missing values on the first of these items, we are only able to use the scores on the second item to proxy for behavioural uncertainty. 


\section{Results}

\subsection{Descriptive statistics}

Table 2, panel A presents summary statistics for each variable.

\section{[INSERT TABLE 2 ABOUT HERE]}

Table 2, panel B presents the correlation matrix. Asset specificity is negatively and significantly associated with the degree of outsourcing $(r=-0.78, p<0.01)$. Asset specificity and behavioural uncertainty are also significantly correlated. The correlations between the exogenous variables are sufficiently low not to prompt any serious multicollinearity concerns.

\subsection{Tests of hypotheses for the full sample}

As a first step in our analysis, we run a multiple OLS regression with the full set of exogenous variables, including the uncertainty-related variables for which we expect that they do not affect sourcing decisions. The results of this regression are reported in table 3, panel A. This initial model includes a number of multiplicative terms to capture the interaction of asset specificity and frequency $(\mathrm{H} 4)$, plus any interactions that might exist between asset specificity and uncertainty ${ }^{6}$. Including these product terms, however, can introduce multicollinearity. To address this problem, we centred (mean-adjusted) the scores on asset specificity, frequency, and the uncertainty proxies prior to forming the multiplicative terms (cf. Aiken \& West, 1991; Jaccard, Turrisi \& Wan, 1990). In addition to centring the variables, we added a constant to the scores for asset specificity to obtain positive values only. This linear transformation has no effect on the estimated coefficients, but facilitates (qualitative) interpretation of the interaction effects. We maintain these practices throughout our analyses. Also, we use White heteroskedasticity-consistent standard errors and covariance in all regressions to correct for heteroskedasticity.

\section{[INSERT TABLE 3 ABOUT HERE]}

Consistent with hypotheses 2 and 3 we find that none of the uncertainty variables has a significant effect on sourcing decisions; neither individually nor in conjunction with asset specificity ${ }^{7}$. The next step is to remove the uncertainty-related variables and their interaction

\footnotetext{
${ }^{6}$ This initial model also tests for any main effects of the uncertainty-related variables EUNC ${ }_{1}$, $\mathrm{EUNC}_{2}$, and BUNC. Although these main effects are not grounded in theoretical TCE (TCE posits that uncertainty is only relevant in conjunction with asset specificity; not in isolation), they must be included in the regression equation to verify that a significant coefficient for an interaction effect is not in fact due to lower order effects (cf. Hartmann \& Moers, 1999).

${ }^{7}$ In section 2.3, we argued that firms that outsource internal auditing experience similar monitoring difficulties to those that choose to internalize this function. The results do not support this contention. Instead, our evidence suggests that the average respondent believes
} 
with asset specificity to arrive at our base model. The base model includes only the factors that we identified as theoretically relevant in explaining internal auditing sourcing decisions, i.e. asset specificity (AS; H1), frequency, (FREQ; H5), and their multiplicative interaction (AS $x$ FREQ; H4). This model is specified as follows:

$$
\text { PROP OUT }=b_{0}+b_{1} \times A S+b_{2} \times \text { FREQ }+b_{3} \times A S \times F R E Q+e
$$

The base model explains $65 \%$ of the variance in outsourced internal auditing (adjusted $R^{2}=0.63$ ). Detailed results of this regression are reported in table 3 , panel $B$. The results provide substantial support for hypotheses $\mathrm{H} 1,4$ and 5 . Consistent with $\mathrm{H} 1$, we find that asset specificity is significantly and negatively associated with the degree of outsourcing $(p=$ 0.0000 ). We also find frequency to be negatively associated with internal auditing outsourcing, as predicted in $\mathrm{H} 5$ ( $\mathrm{p}=0.0001$, one-tailed). Finally, we find support for $\mathrm{H} 4$, stating that the effect of a change in asset specificity on the degree of outsourcing is larger when frequency is low than when frequency is high ( $p=0.0001$, one-tailed). Figure 2 visualizes the interaction effect ${ }^{8}$ by plotting the proportion of outsourcing as a function of asset specificity at different levels of frequency.

\section{[INSERT FIGURE 2 ABOUT HERE]}

Like most empirical studies in management accounting research ${ }^{9}$, our base model suggests that the relations we are trying to capture are linear. The facts, however, indicate otherwise. In our data, we observe that firms choose fully to internalize internal auditing above some threshold level of asset specificity. This threshold level lies well below the maximum level of asset specificity as we measure it. Therefore, we also estimate a non-linear model to test our hypotheses. This model takes the following form:

$$
\text { PROP OUT }=1 /\left\{1+\exp ^{\left(b_{0}+b_{1} \times A S+b_{2} \times \text { FREQ }+b_{3} \times A S \times F R E Q\right)}\right\}+e
$$

Table 4 presents the results. As expected, the non-linear specification improves model fit $\left(R^{2}\right.$ $=0.81$; adjusted $R^{2}=0.80$ ), and reinforces our earlier conclusions for the hypotheses $H 1,4$, and 5 . The coefficients for asset specificity $(p=0.0249$, one-tailed), frequency $(p=0.0595$,

that monitoring the performance of the internal audit function is slightly easier if this function is internalized. This relative monitoring advantage does, however, not influence the sourcing decision -perhaps because reputation concerns compensate for the monitoring disadvantage associated with outsourcing as suggested in section 2.3.

${ }^{8}$ In figure 2, the qualifiers 'high' and 'low' are defined as the mean plus or minus one standard deviation.

${ }^{9}$ In their review of management accounting research, Luft \& Shields (2003) found that only $1 \%$ of the nearly 600 tests they included in their study specify non-linear relations. See also Ittner \& Larcker (2001). 
one-tailed), and their interaction ( $p=0.0779$, one-tailed) remain significant in the hypothesized direction ${ }^{10}$.

\section{[INSERT TABLE 4 ABOUT HERE]}

\subsection{Test of hypotheses for the sub-sample of co-sourcers}

Our sample includes 32 firms that have fully insourced the internal audit function, while 4 firms source all their internal audit services from external supplies. A total of 30 firms partly rely on external providers, but perform other parts of their internal audit function internally. It is possible that the results of the tests we performed so far are strongly influenced by this particular distribution of sourcing behaviour. To assess the stability of our findings, we rerun our base model regressions, only using the sub-sample of co-sourcers, i.e. the firms that combine outsourcing and internally serviced internal auditing. This group of co-sourcers is interesting, for it may be argued that for this group, the validity of the questionnaire responses (and our construct measures) is larger -especially regarding asset specificity. The reason for this is that as we have asked our respondents to answer a number of questions both for outsourced and for insourced auditing activities, firms that either outsource all or none of their internal auditing were forced to report hypothetical scores. Only the co-sourcers were able to give experience-based answers to all survey questions. In addition, following W\&S, we coded the values as zeros for respondents that either outsource all or no internal auditing for a number of other survey items. This procedure inflates asset specificity scores of firms adopting a 'pure' sourcing strategy relative to the co-sourcing group.

In the analysis of the sub-sample of co-sources, we (again) use mean-adjusted data (recalculated based on the raw scores for the sub-sample only). We retain our original variable compositions, after verifying continued construct reliability (for asset specificity and frequency, the newly computed Cronbach's alphas are 0.884 and 0.901 respectively). Table 5 presents the results of the base model regression for the sub-sample of co-sourcing firms. Apparently, our earlier findings are quite stable indeed. Again, we find support for hypotheses $\mathrm{H} 1,4$, and 5 . The coefficients for asset specificity, frequency, and their interaction still have the proper sign, and they remain significant at fully acceptable confidence levels. However, the regression equation fits the data less well. Our model explains only $22 \%$ of the variance in sourcing behaviour in the sub-sample of co-sourcers (adjusted $R^{2}=0.13$ ) ${ }^{11}$. This might be an effect of the smallness of the sub-sample, but it is also possible that the full sample results overstate the explanatory power of our TCE variables as a consequence of measurement issues.

\section{[TAKE IN TABLE 5 ABOUT HERE]}

\footnotetext{
${ }^{10}$ Please note that in the non-linear model, a positively signed coefficient implies that the degree of outsourcing decreases as the independent variable increases.

${ }^{11}$ Respecification of the regression equation helps to improve model fit. For instance, a cubic root transformation of the dependent variable increases $R^{2}$ to $30 \%$ (adjusted $R^{2}=0.22$ ). This model leads us to accept the same hypotheses (all p's $<0.01$ ).
} 


\section{Conclusions and discussion}

Building from earlier research by Widener \& Selto (1999), this study examined internal auditing sourcing decisions, using data from 66 firms headquartered in the Netherlands. Based on TCE, we hypothesized that asset specificity and frequency of internal auditing needs -both individually and in interaction- help to explain organizations' sourcing behaviour with respect to internal auditing. We further hypothesized that neither environmental uncertainty, nor behavioural uncertainty affect internal auditing decisions in any significant way. We tested these hypotheses in various regression models, and found considerable support for the TCEbased explanation in all models. Thus, we found asset specificity to be significantly associated with the organization of internal auditing activities. If internal auditing requires firmspecific knowledge and if the auditing function becomes more integrated with the management and operations of the firm, organizations are more likely to internalize internal auditing. Also, we found that frequency is significantly associated with the sourcing strategy. Larger firms and firms that are relatively heavy consumers of internal auditing services tend to rely more on internal provision of these services, whereas smaller firms that are less auditintensive are more likely to seek external supply. In addition, we found that the interaction of asset specificity and frequency significantly affects internal audit sourcing behaviour, suggesting that as expected, firms weigh the set-up cost of specialized governance when considering their sourcing options. And finally, we found no evidence of environmental of behavioural uncertainty influencing internal audit sourcing -neither as such nor in interaction with asset specificity. This last finding seems to contradict TCE's default position on the effect of uncertainty on governance, but it is in fact fully consistent with our application of TCE's general logic to the specific case of internal audit sourcing behaviour.

These results closely match Widener \& Selto's (1999) findings, strengthening their overall conclusion that "concerns for the transaction costs caused by dimensions of asset specificity and frequency, both as main effects and interactions, influence the decision to outsource internal auditing" (Widener \& Selto, 1999: 66). Because our study replicates their findings in a fully independent sample, at a different moment in time, and in a different institutional context, our study mitigates potential concerns as to the generalizability and (continued) validity of the original W\&S study.

This study has several limitations that should be recognized when interpreting the evidence in this paper. The size of our sample, however, is not a major concern. As our results are fully consistent with the earlier findings of the W\&S study, there is little reason to worry about sampling bias. Nevertheless, a larger sample size would have allowed an examination of additional factors that may be relevant in explaining internal audit sourcing, as for instance industry effects.

Remaining caveats include the following. Even though the hypotheses are built on efficiency arguments, the study does not establish the actual efficiency of observed sourcing practices. Therefore, while we found that firms behave pretty much as predicted, we cannot conclude that their sourcing decisions are rooted in efficiency motives. Neither can we conclude that a theoretically consistent alignment between an organization's internal auditing activities and its sourcing strategy is in fact efficient. In addition, as the research design is 
purely cross-sectional, our study provides evidence on associations, not on causal relations. For this reason, the significant and negative relation between for instance asset specificity and outsourcing we documented cannot buttress the conjecture that a higher level of asset specificity actually causes a preference for internal sourcing of auditing services. In fact, alternative explanations are possible. For example, it could be the case that the presence of an internal audit department results in audit activities that are more tailored to the specifics of the firm. Similarly, outsourcing may lead to a more generic approach to internal auditing. Consequently, what we pick up as high or low levels of specificity may be a consequence rather than an antecedent of the internal audit sourcing decision. The data do not allow us to differentiate between this alternative explanation and the theoretical model.

Further research is necessary to redress the limitations of this study and to fill remaining knowledge gaps. A longitudinal study examining changes in internal auditing sourcing behaviour over time may shed light on the issue of causality. Additionally, researchers may seek to address the relative performance of internal auditing under different governance regimes in different situations. Such research, however, requires operationalizing internal audit effectiveness and is bound to pose extremely challenging measurement issues. A less assuming research agenda might include studies that further examine the role of uncertainty in organizing internal auditing. We found some evidence that monitoring the performance of the internal audit function is easier if this function is internalized. These better monitoring properties, however, do not seem to affect sourcing decisions. This suggests that outsourcing offers some advantage to compensate for monitoring. A deeper insight in these matters would be welcome. A final suggestion for future research relates to the observation that a significant proportion of firms ( $43 \%$ of respondents) report not to use internal auditing services at all. Given the importance the internal audit function, our guess would be that these non-users have found some substitute for internal auditing elsewhere in their control structure (cf. also Widener \& Selto, 1999). This guess could be explored in a study examining internal auditing explicitly as part of a larger management control structure, i.e. as an element of an organizational control package (Otley, 1980; Speklé, 2001). Such a perspective may greatly enhance our understanding of the role of internal auditing in the functioning of organizations.

\section{References}

Ahlawat, S.S. and Lowe, D.J. 2004. An examination of internal auditor objectivity: In-house versus outsourcing. Auditing: A Journal of Practice \& Theory, 23(2): 147-158.

Aiken, L.S. and West, S.G. 1991. Multiple regression: Testing and interpreting interactions. Newbury Park: Sage Publications.

Aldhizer, G.R., Cashell, J.D. and Martin, D.R. 2003. Internal audit outsourcing. CPA Journal, 73(8): 38-42.

Arruñada, B. 2000. Audit quality: attributes, private safeguards and the role of regulation. European Accounting Review, 9: 205-224.

Barr, R.H. and Chang, S.Y. 1993. Outsourcing internal audits: A boon or bane? Managerial Auditing Journal, 8: 14-17. 
Boerner, C.S. and Macher, J.T. 2002. Transaction cost economics: An assessment of empirical research in the social sciences. Working paper.

Caplan, D.H. and Kirschenheiter, M. 2000. Outsourcing and audit risk for internal audit services. Contemporary Accounting Research, 17: 387-428.

Chadwick, W.E. 2000. Keeping internal auditing in-house. Internal Auditor, 57(3): 88.

Covaleski, M.A., Dirsmith, M.W. and Rittenberg, L. 2003. Jurisdictional disputes over professional work: The institutionalization of the global knowledge expert. Accounting, Organizations and Society, 28: 323-355.

David, R.J. and Han, S. 2004. A systematic assessment of the empirical support for transaction cost economics. Strategic Management Journal, 25: 39-58.

DeAngelo, L.E. 1981. Auditor size and audit quality. Journal of Accounting and Economics, 3: 183-199.

Hartmann, F.G.H. and Moers, F. 1999. Testing contingency hypotheses in budgetary research: An evaluation of the use of moderated regression analysis. Accounting, Organizations and Society, 24: 291-315.

IIA (Institute of Internal Auditors). 1998. A perspective on outsourcing of the internal audit function, Professional Practices Pamphlet 98-1, www.theiia.org.

Ittner, C.D. and Larcker, D.F. 2001. Assessing empirical research in managerial accounting: A value-based management perspective. Journal of Accounting and Economics, 32: 349410.

Jaccard, J., Turrisi, R. and Wan, C.K. 1990. Interaction effects in multiple regression. Newbury Park: Sage Publications.

Luft, J. and Shields, M.D. 2003. Mapping management accounting: Graphics and guidelines for theory-consistent empirical research. Accounting, Organizations and Society, 28: 169249.

Martin, C.L. and Lavine, M.K. 2000. Outsourcing the internal audit function. CPA Journal, 70(2): 58-59.

Merchant, K.A. 1985. Control in business organizations. New York: Ballinger Publishing Company.

Nooteboom, B. 1993. Research note: An analysis of specificity in transaction cost economics. Organization Studies, 14: 443-451.

Otley, D.T. 1980. The contingency theory of management accounting: achievement and prognosis. Accounting, Organizations and Society, 5: 413-428.

Petravick, S. 1997. Outsourcing internal audit isn't only the big firms' game. CPA Journal, 67(5): 62-63.

Rittenberg, L.E. and Covaleski, M. 1999. Outsourcing the internal audit function: The British government experience with market testing. International Journal of Auditing, 3: 225-235.

Rittenberg, L. and Covaleski, M.A. 2001. Internalization versus externalization of the internal audit function: An examination of professional and organizational imperatives. Accounting, Organizations and Society, 26: 617-641.

Speklé, R.F. 2001. Explaining management control structure variety: a transaction cost economics perspective, Accounting, Organizations and Society, 26, 419-441. 
Widener, S.K. and Selto, F.H. 1999. Management control systems and boundaries of the firm: Why do firms outsource internal audit activities? Journal of Management Accounting Research, 11: 45-73.

Williamson, O.E. 1975. Markets and hierarchies: analysis and antitrust implications. New York: Free Press.

Williamson, O.E. 1985. The economic institutions of capitalism. New York: Free Press.

Williamson, O.E. 1991. Comparative economic organization: The analysis of discrete structural alternatives. Administrative Science Quarterly, 36: 269-296.

Williamson, O.E. 1996. The mechanisms of governance. New York: Oxford University Press.

Williamson, O.E. 1999. Strategy research: Governance and competence perspectives. Strategic Management Journal, 20: 1087-1108. 
FIGURE 1

Synopsis of expectations

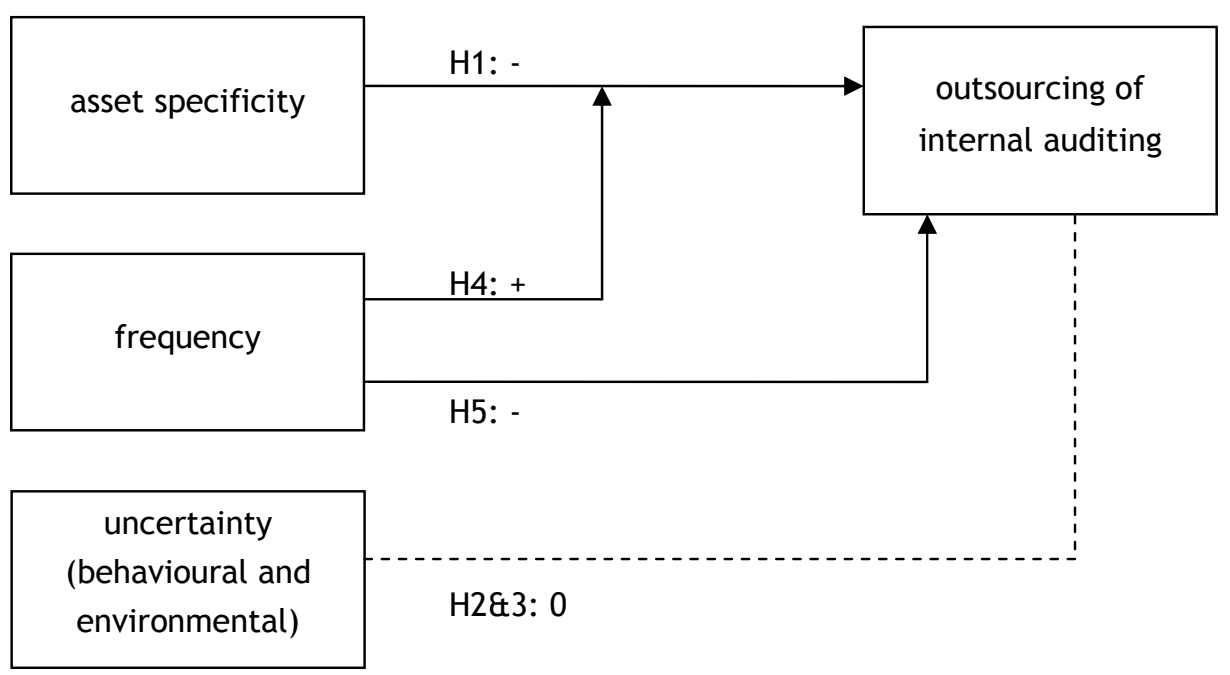


FIGURE 2

Interaction effect of asset specificity and frequency

\begin{tabular}{|rr|c|c|c|}
\hline & & \multicolumn{4}{|c|}{ Interaction effect } \\
\hline & 0.6 & & & \\
\hline
\end{tabular}


TABLE 1

Composition and reliability of variables

\begin{tabular}{|c|c|c|}
\hline & Items & Cronbach's a \\
\hline Asset specificity & $\begin{array}{l}\text { - } \text { operational versus financial audits } \\
\text { - } \text { reliance on proprietary information } \\
\text { - contribution to firm credibility by ensuring compli- } \\
\text { - } \text { ance with policies and procedures } \\
\text { - } \text { degree of interaction with management } \\
\text { - contribution to achievement of strategic plans } \\
\text { - contribution to identification of process improve- } \\
\text { - } \text { ment potential } \\
\text { - } \text { contribution to identification of market opportuni- } \\
\text { grammes }\end{array}$ & 0.976 \\
\hline Frequency & $\begin{array}{ll}\text { - } & \text { sales } \\
\text { - } & \text { number of employees } \\
\text { - } & \text { number of internal auditing reports } \\
\text { - } & \text { number of internal auditing engagements }\end{array}$ & 0.891 \\
\hline
\end{tabular}


TABLE 2

Descriptive statistics and correlations

Panel A: Descriptive statistics

\begin{tabular}{|l|c|c|c|c|c|}
\hline Variable & Mean & Std. Dev. & Minimum & Median & Maximum \\
\hline PROP OUT & 0.156 & 0.278 & 0.000 & 0.008 & 1.000 \\
AS & 1.718 & 2.100 & -3.400 & 2.400 & 4.300 \\
EUNC $_{1}$ & 2.700 & 1.176 & 1.000 & 2.000 & 5.000 \\
EUNC $_{2}$ & 2.390 & 0.953 & 1.000 & 2.000 & 5.000 \\
BUNC & 2.700 & 0.710 & 1.000 & 3.000 & 5.000 \\
FREQ & 0.000 & 0.856 & -0.380 & -0.245 & 5.720 \\
\hline Individual items comprising FREQ: & & & & \\
\hline Sales (x $€ 1,000)$ & $2,834,021$ & 6,632869 & 7,424 & & $2,693,000$ \\
Employees & 12,980 & 39,137 & 101 & & 750 \\
Reports & 40 & 107 & 1 & & 750 \\
Engagements & 31 & 98 & 1 & & \\
\hline
\end{tabular}

Panel B: Correlation matrix

\begin{tabular}{|c|c|c|c|c|c|c|}
\hline & 1 & 2 & 3 & 4 & 5 & 6 \\
\hline 1: PROP OUT & 1 & & & & & \\
\hline 2: AS & $-0.777^{*}$ & 1 & & & & \\
\hline 3: $\mathrm{EUNC}_{1}$ & 0.044 & -0.081 & 1 & & & \\
\hline 4: $\mathrm{EUNC}_{2}$ & 0.004 & -0.050 & 0.174 & 1 & & \\
\hline 5: BUNC & 0.205 & $-0.296^{*}$ & 0.128 & 0.036 & 1 & \\
\hline 6: FREQ & -0.132 & -0.039 & 0.162 & 0.009 & -0.041 & 1 \\
\hline
\end{tabular}

* Correlation is significant at the 0.01 level (2-tailed). 


\section{TABLE 3}

Results of multiple regression analysis: initial and base model (all firms)

Panel A: Initial model

Dependent Variable: Proportion of outsourcing

Method: Least Squares

Sample: 66

Included observations: 61

White Heteroskedasticity-Consistent Standard Errors \& Covariance

\begin{tabular}{lcccc}
\hline \hline & Coefficient & Std. Error & t-Statistic & Prob. (2-tailed) \\
\hline \hline Intercept & 0.140 & 0.023 & 6.190 & 0.0000 \\
AS & -0.094 & 0.013 & -7.332 & 0.0000 \\
BUNC & 0.097 & 0.131 & 0.741 & 0.4623 \\
EUNC $_{1}$ & -0.071 & 0.065 & -1.081 & 0.2848 \\
EUNC $_{2}$ & -0.045 & 0.077 & -0.583 & 0.5623 \\
FREQ & -0.109 & 0.045 & -2.460 & 0.0173 \\
AS X BUNC & 0.016 & 0.011 & 1.504 & 0.1387 \\
AS X EUNC & 0.006 & 0.012 & 0.538 & 0.5928 \\
AS X EUNC 2 & -0.023 & 0.019 & -1.209 & 0.2321 \\
AS X FREQ & 0.017 & 0.009 & 1.904 & 0.0625 \\
\hline \hline R-squared & 0.639 & Adjusted R-squared & 0.576 \\
\hline \hline
\end{tabular}

Panel B: Base model

Dependent Variable: Proportion of outsourcing

Method: Least Squares

Sample: 66

Included observations: 66

White Heteroskedasticity-Consistent Standard Errors \& Covariance

\begin{tabular}{lcccc}
\hline \hline & Coefficient & Std. Error & t-Statistic & Prob. (1-tailed) \\
\hline \hline Intercept & 0.159 & 0.021 & 7.580 & 0.0000 \\
AS & -0.100 & 0.012 & -8.080 & 0.0000 \\
FREQ & -0.178 & 0.042 & -4.237 & 0.0001 \\
AS x FREQ & 0.034 & 0.008 & 4.064 & 0.0001 \\
\hline \hline R-squared & 0.646 & Adjusted R-squared & 0.629 \\
\hline \hline
\end{tabular}


TABLE 4

Results of multiple regression analysis: non-linear model (all firms)

Dependent Variable: Proportion of outsourcing

Method: Least Squares

Sample: 66

Included observations: 66

White Heteroskedasticity-Consistent Standard Errors \& Covariance

\begin{tabular}{lcccc}
\hline \hline & Coefficient & Std. Error & t-Statistic & Prob. (1-tailed) \\
\hline \hline Intercept & 4.426 & 1.596 & 2.773 & 0.0037 \\
AS & 2.032 & 1.015 & 2.001 & 0.0249 \\
FREQ & 4.003 & 2.531 & 1.581 & 0.0595 \\
AS x FREQ & -1.053 & 0.733 & -1.437 & 0.0779 \\
\hline \hline R-squared & 0.809 & Adjusted R-squared & 0.800 \\
\hline \hline
\end{tabular}




\section{TABLE 5}

Results of multiple regression analysis: base model (co-sourcers only)

Dependent Variable: Proportion of outsourcing

Method: Least Squares

Sample: 30

Included observations: 30

White Heteroskedasticity-Consistent Standard Errors \& Covariance

\begin{tabular}{lcccc}
\hline \hline & Coefficient & Std. Error & t-Statistic & Prob. (1-tailed) \\
\hline \hline Intercept & 0.206 & 0.035 & 5.849 & 0.0000 \\
AS & -0.200 & 0.086 & -2.333 & 0.0139 \\
FREQ & -0.121 & 0.045 & -2.684 & 0.0063 \\
AS x FREQ & 0.232 & 0.126 & 1.832 & 0.0392 \\
\hline \hline R-squared & 0.220 & Adjusted R-squared & 0.130 \\
\hline \hline
\end{tabular}

